\title{
Improvement of mortar durability by electrochemical technique
}

\section{Hongyou Shan}

College of Mechanics and Materials, Hohai University, Nanjing, PR China Jinxia Xu

College of Mechanics and Materials, Hohai University, Nanjing, PR China (corresponding author: xujinxia@hhu.edu.cn)
Linhua Jiang

College of Mechanics and Materials, Hohai University, Nanjing, PR China Zhuyin Wang

College of Mechanics and Materials, Hohai University, Nanjing, PR China

An electrochemical technique was applied to improve mortar durability. Silicate ions were injected into mortar pores to react with calcium hydroxide by applying an electric field, resulting in densification of the mortar. The calcium ions in the pores of the mortar were electro-transported to the sodium silicate solution, which led to the formation of a surface coating. The durability of mortars after electrochemical treatment was evaluated by examining water absorption, carbonation depth, sulfate resistance and chloride diffusion. In addition, microscopic observations were made using scanning electron microscopy, mercury intrusion porosimetry, thermogravimetric analysis and differential scanning calorimetry. The results indicated that the resistances to water absorption, carbonation, sulfate and chloride diffusion were improved by use of the electrochemical technique. The improvement in mortar durability was attributed to the combined actions of densification and the coating layer produced on the mortar surface during the electrochemical treatment. However, the coating layer, being thin and of high porosity, played only a minor role.

\author{
Notation \\ $C(x, t) \quad$ chloride concentration at depth $x$ and time $t(\%)$ \\ $C_{\mathrm{s}} \quad$ chloride concentration at mortar surface (\%) \\ $D \quad$ effective chloride diffusion coefficient $\left(\mathrm{cm}^{2} / \mathrm{s}\right)$ \\ $f_{\mathrm{s}} \quad$ flexural strength of mortar sample in sodium sulfate \\ solution (MPa) \\ $f_{\mathrm{s}}^{\prime} \quad$ flexural strength of mortar sample in water (MPa) \\ $K \quad$ water absorption coefficient $\left(\left(\mathrm{kg} / \mathrm{m}^{2}\right) / \mathrm{h}^{1 / 2}\right)$ \\ $m \quad$ weight loss of mortar sample at a certain test age (\%) \\ $m_{1} \quad$ weight of mortar sample before immersion in an \\ aggressive environment $(\mathrm{kg})$ \\ $m_{2} \quad$ weight of mortar sample after immersion in an \\ aggressive environment $(\mathrm{kg})$ \\ Q/a amount of absorbed water per unit surface $\left(\mathrm{kg} / \mathrm{m}^{2}\right)$ \\ $S \quad$ resistance modulus of flexural strength (\%) \\ $t \quad$ time of exposure (h) \\ $x \quad$ depth from mortar surface $(\mathrm{mm})$
}

\section{Introduction}

Concrete is widely used as a major building material owing to its excellent performance and relatively low cost. However, concrete has a porous structure, which provides convenient transport channels for aggressive media such as water, oxygen, carbon dioxide, chloride ions and sulfate ions. Concrete subjected to severe environments can thus suffer from early deterioration (e.g. corrosion of steel reinforcement, freezing and thawing damage, sulfate attack), meaning that its service life is reduced. The durability of concrete structures is thus of great interest and concern to researchers all over the world (Badogiannisa et al., 2015; Shi et al., 2012).

Various methods are employed to reduce the permeability of concrete and thus improve the durability of concrete structures (Almusallam et al., 2003; Faleschini et al., 2015; Medin et al.,
2015). Among these methods, the fabrication of concrete with a small pore size and low porosity is generally considered to be an effective approach. This can be achieved by decreasing the water/cement (w/c) ratio and adding sufficient mineral admixtures and water reducing agents in the concrete mix proportion (Bharatkumar et al., 2001; Neville and Aitcin, 1998). However, in using this method, the autogenous shrinkage of concrete simultaneously increases, meaning that the concrete is vulnerable to cracking at an early age, which is detrimental to the durability of the concrete structure. In practical engineering, surface coatings and penetrating sealers are widely used (Abuawad et al., 2015; Pritzl et al., 2015). However, these techniques are time consuming and they rely on the surrounding environment. New techniques to improve concrete durability are thus required.

The electrodeposition method has been successfully applied to repair cracks in concrete (Chu et al., 2014; Ryu and Otsuki, 2002) and it has been also reported that this technique can make concrete denser so that its durability is greatly improved (Jiang et al., 2008; Ryou and Otsuki, 2005). However, the electrodeposition products in concrete pores are different from the concrete composition and the electrodeposition method can cause acidification of concrete (Ryu and Otsuki, 2002). Due to these factors, $\mathrm{Xu}$ et al. (2016) proposed an electrochemical technique that deposits cementitious materials and improves concrete alkalinity. In this technique, silicate ions are injected into mortar pores to react with calcium hydroxide and this results in densification of the mortar by applying an electric field. Calcium ions in the mortar pores are electrotransported to the sodium silicate solution, leading to the formation of a surface coating. This technique has been shown to greatly improve mortar resistivity and has great potential for improving mortar durability (Xu et al., 2016). 
The objective of the work reported in this paper was to assess the effect of this electrochemical technique on improving the durability of mortars with different w/c ratios. The durability of mortars after electrochemical treatment was evaluated by examining water absorption, carbonation depth, sulfate resistance and chloride diffusion. Microscopic observations were conducted by means of scanning electron microscopy (SEM), mercury intrusion porosimetry (MIP), thermogravimetric analysis (TGA) and differential scanning calorimetry (DSC).

\section{Experimental details}

\section{Materials}

The cement used in this study was 42.5 ordinary Portland cement. Its oxide composition is given in Table 1. River sand with a fineness modulus of $2 \cdot 1$ was used as fine aggregate. Tap water was used to prepare the mortars while distilled water was used to prepare the electrolytic solutions (saturated calcium hydroxide and sodium silicate).

\section{Electrochemical treatment}

Mortar samples of size $4 \mathrm{~cm} \times 4 \mathrm{~cm} \times 16 \mathrm{~cm}$ were fabricated at w/c ratios of 0.45 and 0.55 and a cement/sand ratio of 0.4 . The mortar samples were removed from their moulds $24 \mathrm{~h}$ after casting and then cured in a $95 \%$ humidity chamber at $20 \pm 2^{\circ} \mathrm{C}$ for $27 \mathrm{~d}$.

Table 1. Oxide composition of cement

$\begin{array}{lr}\text { Silicon dioxide }\left(\mathrm{SiO}_{2}\right): \% \mathrm{w} / \mathrm{w} & 22.97 \\ \text { Aluminium oxide }\left(\mathrm{Al}_{2} \mathrm{O}_{3}\right): \% \mathrm{w} / \mathrm{w} & 9.28 \\ \text { Calcium oxide }(\mathrm{CaO}): \% \mathrm{w} / \mathrm{w} & 59.68 \\ \text { Iron oxide }\left(\mathrm{Fe}_{2} \mathrm{O}_{3}\right): \% \mathrm{w} / \mathrm{w} & 3.10 \\ \text { Potassium oxide }\left(\mathrm{K}_{2} \mathrm{O}\right): \% \mathrm{w} / \mathrm{w} & 1.03 \\ \text { Magnesium oxide }(\mathrm{MgO}): \% \mathrm{w} / \mathrm{w} & 1.73 \\ \text { Sulfur trioxide }\left(\mathrm{SO}_{3}\right): \% \mathrm{w} / \mathrm{w} & 1.23 \\ \text { Loss on ignition: \% w/w } & 0.98\end{array}$

After curing, each mortar sample was installed in the middle of a Perspex electrolytic tank $(24 \mathrm{~cm} \times 16 \mathrm{~cm} \times 4 \mathrm{~cm})$. Titanium meshes were used as the anode and cathode. Saturated calcium hydroxide and electrolytic solutions of sodium silicate (concentrations $0.05 \mathrm{~mol} / \mathrm{l}$ ) were respectively added to the anodic and cathodic compartments. The experimental arrangement is detailed in Figure 1. The applied voltage and conduction time were $24 \mathrm{~V} / \mathrm{cm}$ and $20 \mathrm{~d}$, respectively. The temperature was controlled at $20 \pm 2^{\circ} \mathrm{C}$ by means of a water bath. These parameters were optimised in previous experiments ( $\mathrm{Xu}$ et al., 2016). The electrolytic solution of sodium silicate was replaced every $3 \mathrm{~d}$ in order in order to maintain a stable composition. Figure 2 shows a typical surface of a mortar sample with a w/c ratio of $0 \cdot 45$, showing the thin (about $1.0 \mathrm{~mm}$ thickness) coating layer on its surface (image a). To evaluate the effectiveness of the electrochemical treatment and the role of the surface coating on the durability, control samples and treated samples with coating removed were also prepared for comparison.

\section{Durability tests}

After undergoing the electrochemical treatment, the durability of the mortars was tested. Before the durability tests, all the mortar surfaces except for the surface with a coating layer formed during the electrochemical treatment were coated with epoxy resin. All experiments were conducted more than three times and the results shown in the figures in this paper are the average values.

\section{Water absorption}

Water absorption testing was conducted in accordance with ISO 15148 (ISO, 2002). A schematic diagram of the water absorption coefficient test is shown in Figure 3. In this test, after drying at $60^{\circ} \mathrm{C}$ for $10 \mathrm{~d}$ until a constant weight was obtained, the mortar surface with a coating layer from the electrochemical treatment was immersed in $5 \mathrm{~mm}$ of water and variations of mass were measured periodically at intervals of

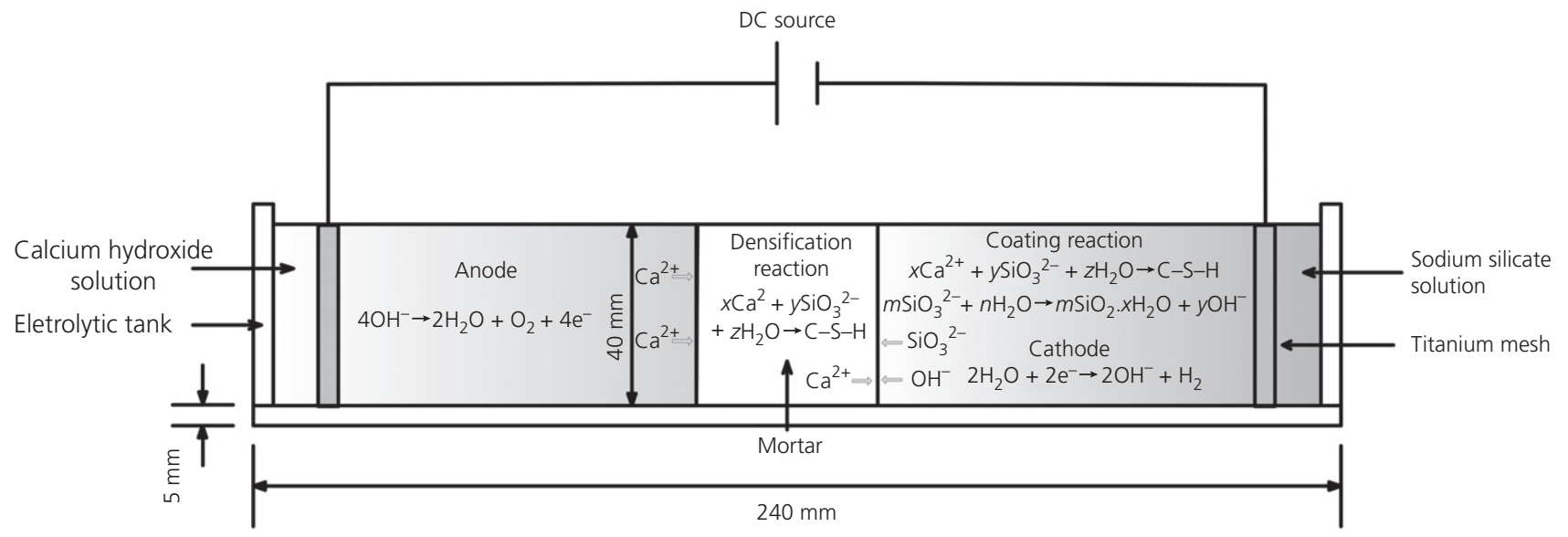

Figure 1. Schematic diagram of experimental arrangement for the electrochemical treatment 
Improvement of mortar durability

by electrochemical technique

Shan, Xu, Jiang and Wang

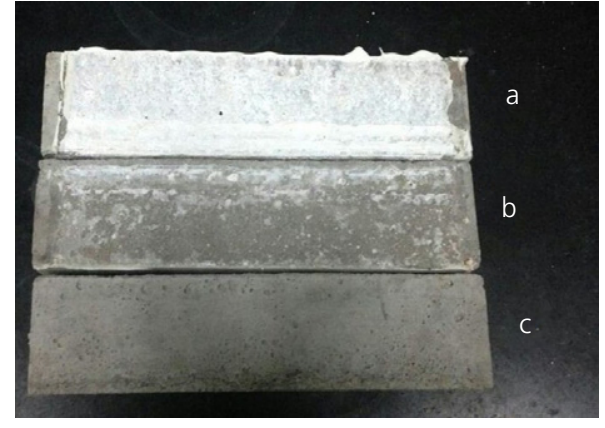

Figure 2. Photographs of typical surfaces of mortar samples with a w/c ratio of $0.45: a$, treated sample; $b$, treated sample with coating removed; c, control sample

20, 40, 60, 80, 120, 160, 200 and $240 \mathrm{~min}$. The water absorption coefficient was calculated from

1. $K \sqrt{t}=\frac{Q}{a}$

where $K$ is the water absorption coefficient $\left(\left(\mathrm{kg} / \mathrm{m}^{2}\right) / \mathrm{h}^{1 / 2}\right)$, $t$ is the time of exposure (h) and $Q / a$ is the amount of absorbed water per unit surface $\left(\mathrm{kg} / \mathrm{m}^{2}\right)$.

\section{Accelerated carbonation}

The mortar samples were positioned in an accelerated carbonation chamber set at a temperature of $20 \pm 5^{\circ} \mathrm{C}$, relative humidity of $70 \pm 5 \%$ and carbon dioxide concentration of $20 \pm 2 \%$. The carbonation depth was measured by means of standard phenolphthalein indicator solution sprayed on a fresh split surface at 3, 7, 14 and $28 \mathrm{~d}$.

\section{Sulfate resistance}

Sulfate resistance testing was carried out by immersing the mortar samples in a $5.0 \%$ sodium sulfate solution (by mass). The mortar samples were retrieved to test for flexural strength and weight loss after 15, 30, 45, 60, 90, 120, 150 and $180 \mathrm{~d}$ of immersion. The flexural strength and weight loss of a control mortar sample immersed in water were also measured.
The resistance modulus of flexural strength was determined by

2. $S=\frac{f_{\mathrm{s}}}{f_{\mathrm{s}}^{\prime}} \times 100$

where $S$ is the resistance modulus of flexural strength $(\%), f_{\mathrm{s}}$ is the flexural strength of the mortar sample in sodium sulfate solution (MPa) and $f_{\mathrm{s}}^{\prime}$ is the flexural strength of the mortar sample in water (MPa).

The weight loss was determined using

3. $m=\frac{m_{1}-m_{2}}{m_{1}} \times 100$

where $m$ is the weight loss of the mortar sample at a certain test age $(\%), m_{1}$ is the weight of the mortar sample before immersion in an aggressive environment $(\mathrm{kg})$ and $m_{2}$ is the weight of the mortar sample after immersion in the aggressive environment $(\mathrm{kg})$.

\section{Chloride-ion diffusion}

Chloride-ion diffusion was measured by immersing mortar samples in a $3 \cdot 5 \%$ sodium chloride solution (by mass) for 3 months. Following this, mortar powders were collected by drilling to various depths $(0-5,5-10,10-15,15-20,20-25$, 25-30, 30-35 and 35-40 mm) from the surface with a coating layer. After passing through a sieve of size $0.16 \mathrm{~mm}, 20 \mathrm{~g}$ of powder was added to $200 \mathrm{ml}$ distilled water. The mixture was vigorously stirred for a period and then left to stand for $24 \mathrm{~h}$. Chloride concentration was determined by potentiometric titration with silver nitrate $\left(\mathrm{AgNO}_{3}\right)$. The chloride diffusion coefficient of the mortar was then determined from the chloride profile by solving Fick's second law of diffusion, given by

4. $C(x, t)=C_{\mathrm{s}}\left[1-\operatorname{erf}\left(\frac{x}{2 \sqrt{D t}}\right)\right]$

where $C(x, t)$ is the chloride concentration (\%) at depth $x$ and time $t, C_{\mathrm{s}}$ is the chloride concentration (\%) at the

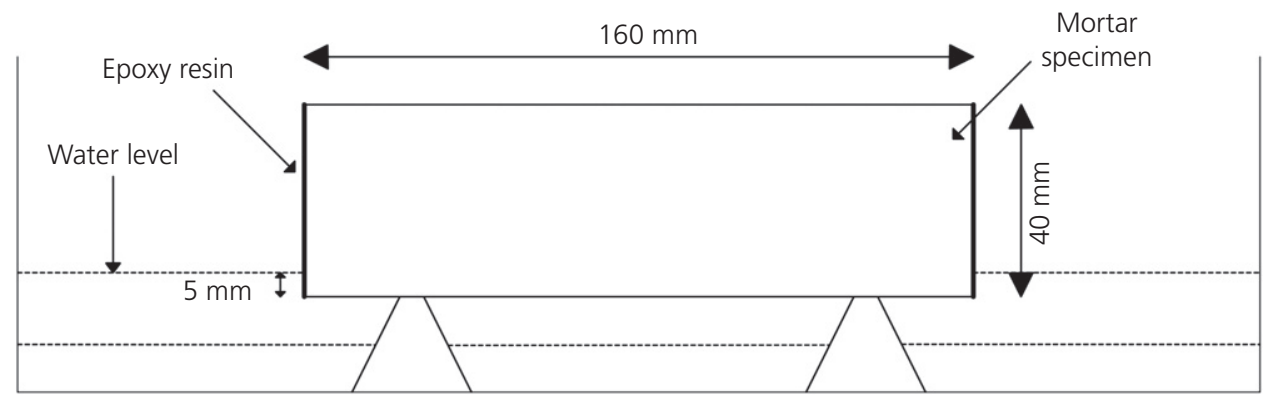

Figure 3. Schematic diagram of water absorption coefficient test 
mortar surface, $x$ is the depth from the mortar surface (mm), $t$ is time (s) and $D$ is the effective chloride diffusion coefficient $\left(\mathrm{cm}^{2} / \mathrm{s}\right)$.

\section{Microscopic observations}

The treated mortar samples (w/c ratio of 0.45 ) and control samples were dried at a temperature of $60^{\circ} \mathrm{C}$ for $7 \mathrm{~d}$. For microscopic observations of the coating layer, small slices were cut from the surface coating layer. Small slices were also cut from the mortar samples and mortar powders were collected for microscopic measurements. SEM was performed (Hitachi$3400 \mathrm{~N}$ ) at an accelerating voltage of $15 \mathrm{kV}$. The pore structure of mortar sample was measured by means of MIP (Poremaster GT-60, Quantachrome Corporation, USA). TGA and DSC tests were performed (STA8000, PerkinElmer corporation, USA) at a heating rate of $10^{\circ} \mathrm{C} / \mathrm{min}$ from $50^{\circ} \mathrm{C}$ to $1000^{\circ} \mathrm{C}$.

\section{Results}

\section{Water absorption}

The results of the capillary water absorption test are shown in Figure 4. The water absorption amount of the treated mortar samples was smaller than that of the control sample at the same immersion time. In addition, the initial water absorption amount of the treated sample was higher than that of the treated sample with coating removed. However, with an increase in water absorption time, the increase rate of water absorption amount for the treated sample decreased. After immersion for $4 \mathrm{~h}$, the water absorption of the treated sample was similar to that of the treated sample with coating removed. The water absorption coefficient of the treated samples was than that of the control sample, and the water absorption coefficient of the treated sample with coating removed was similar to that of the treated sample. Comparing Figures 4(a) and 4(b), the reductions in water absorption coefficient of the treated mortars with w/c ratios of 0.45 and 0.55 were $47.4 \%$ and $38.1 \%$, respectively. In other words, the reduction in the water absorption coefficient of the treated mortar with a w/c ratio of 0.45 was greater than that of the treated mortar with a w/c ratio of $0 \cdot 55$.

\section{Carbonation}

Figure 5 shows the carbonation depths of the control mortar and treated mortars as-obtained and with the coating removed. Compared with the control mortar, the carbonation depths of the treated mortar samples were smaller at the same carbonation time. For example, at $28 \mathrm{~d}$, the carbonation depth of the control mortar with a w/c ratio of 0.45 was $18.7 \mathrm{~mm}$ while the carbonation depth of the treated mortar was $10.4 \mathrm{~mm}$. The difference in carbonation depth between the treated mortar and the treated mortar with coating removed was small. Comparing Figures 5(a) and 5(b), the reduction in carbonation depth (compared with the control mortar) of the treated mortar with a w/c ratio of 0.45 at $28 \mathrm{~d}$ was $44.4 \%$ while that of the $w / c=0.55$ mortar was $35 \cdot 5 \%$.

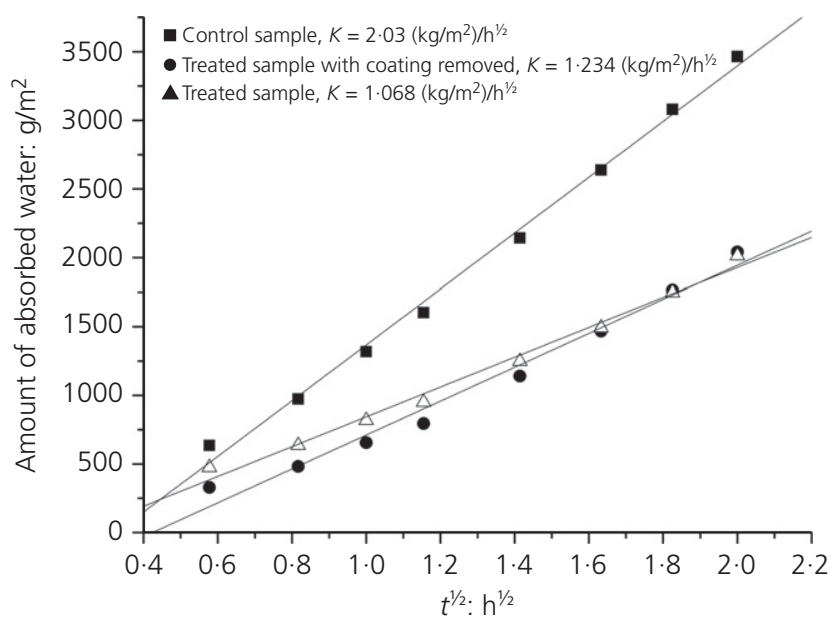

(a)

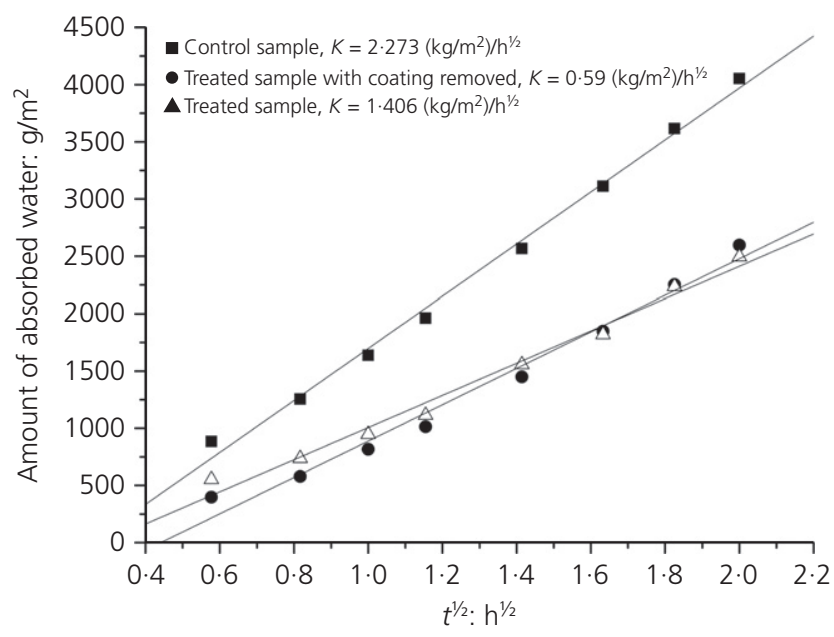

(b)

Figure 4. Change in water absorption with time: $(a) w / c=0.45$; (b) $w / c=0.55$

\section{Sulfate resistance}

In the process of sulfate attack, sulfates react with cement hydration products, leading to the formation of ettringite or gypsum, which fills the pores of the mortar. Due to the more compact structure of the mortar, its flexural strength will improve. However, if ettringite or gypsum continues to be generated, internal stresses in the mortar pores will increase. When the accumulated internal stress is more than the tensile strength of mortar, the mortar will crack and then the flexural strength of the mortar will be greatly reduced. Figure 6 shows the resistance modulus of flexural strength of the control mortar, the treated mortar and the treated mortar with coating removed at various immersion times. The resistance modulus of flexural strength of the mortars increased during the early stages of immersion (up to $30 \mathrm{~d}$ ). With increasing immersion time, the resistance modulus of flexural strength of the control mortar decreased rapidly. The resistance moduli of flexural strength of the treated mortar and the treated mortar with coating 
Improvement of mortar durability

by electrochemical technique

Shan, Xu, Jiang and Wang

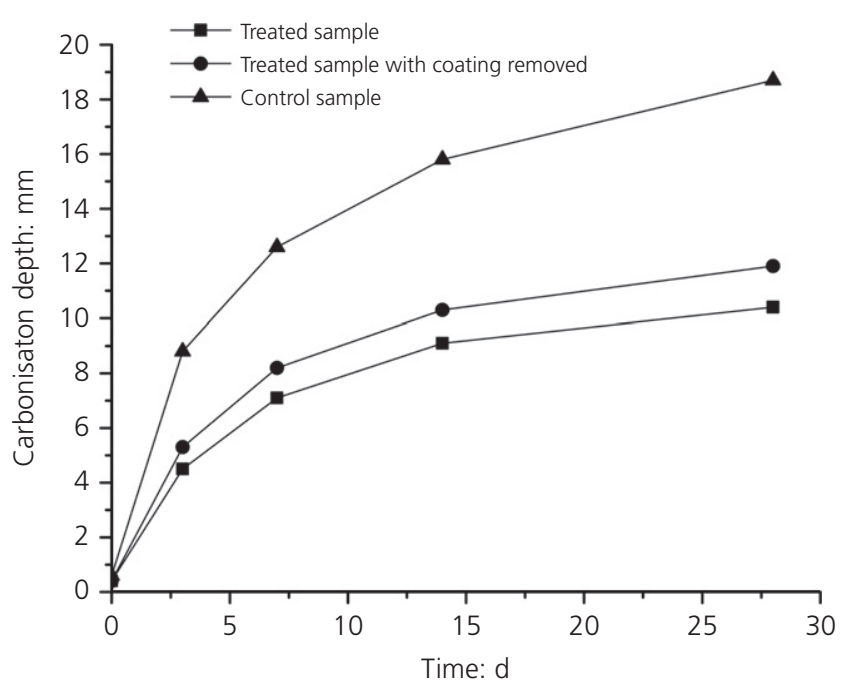

(a)

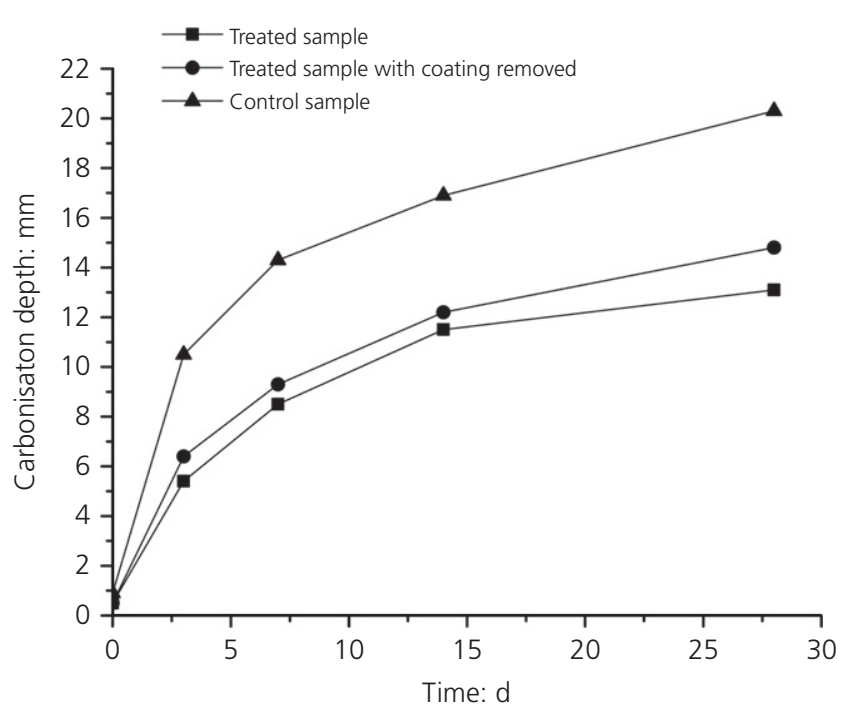

(b)

Figure 5. Change in carbonation depth with time: (a) $w / c=0.45$; (b) $w / c=0.55$

removed showed a gentle decrease with immersion time, and the values were higher than that of the control sample during the later periods of immersion. The reductions in resistance modulus of flexural strength of the treated mortars with w/c ratios of 0.45 and 0.55 decreased by $77 \%$ and $57.9 \%$, respectively.

Figure 7 shows the weight losses of the mortars at various immersion times. The weight of the mortars increased during the early stage of immersion (up to $30 \mathrm{~d}$ ), after which the weight loss of the control mortar increased significantly. The electrochemically treated mortars exhibited gentle changes with immersion time. After immersion for $180 \mathrm{~d}$, the weight loss of the control sample was higher than that of the treated mortar and the treated mortar with coating removed.

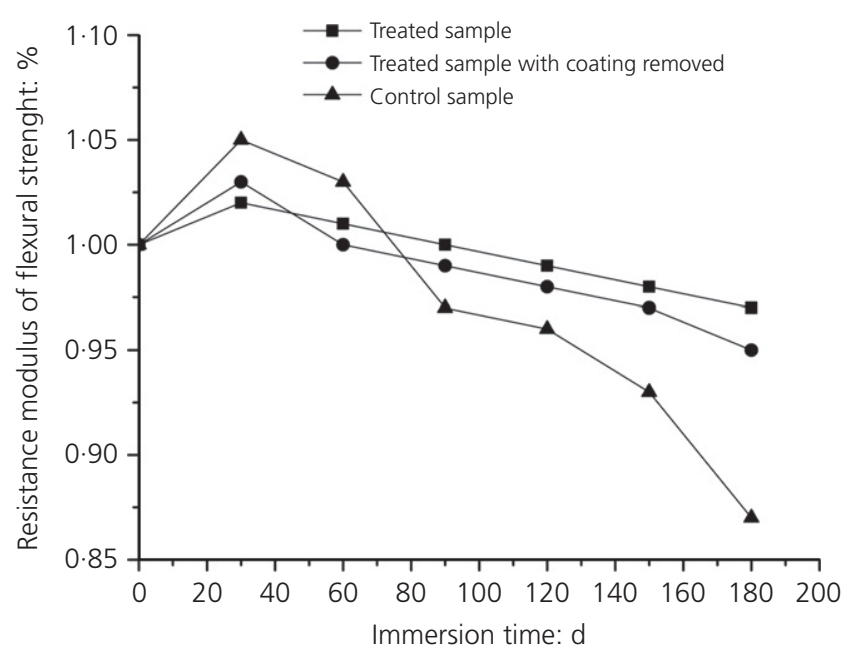

(a)

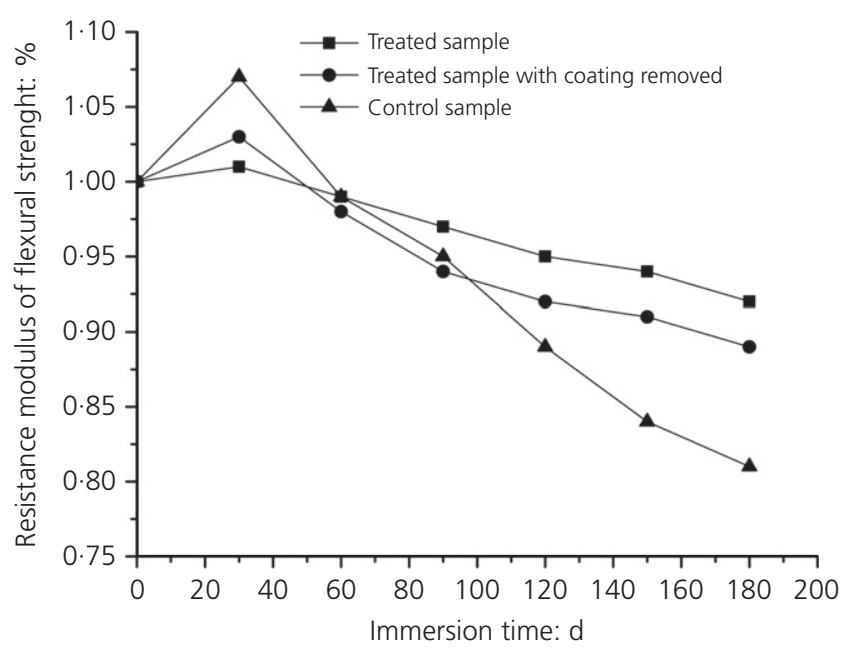

(b)

Figure 6. Change in resistance modulus of flexural strength with immersion time: (a) $w / c=0.45$; (b) $w / c=0.55$

Comparing Figures 7(a) and 7(b), the reductions in weight loss of the treated mortars with w/c ratios of 0.45 and 0.55 were $60 \cdot 8 \%$ and $48 \cdot 7 \%$, respectively. There were only small differences in weight loss between the treated mortar and the treated mortar with coating removed.

\section{Chloride-ion diffusion}

The profiles of free chloride ions of the control mortar, the treated mortar and the treated mortar with coating removed are presented in Figure 8. It can be seen that the chloride contents of all mortar samples decreased with increasing depth, with the chloride content of the treated mortars lower than that of the control mortar at the same depth. The chloride diffusion coefficients of the mortar samples obtained from curve fitting of the chloride profiles according to Fick's second law are shown in Figure 9. The chloride diffusion coefficients of the treated mortars were smaller than that of the control 


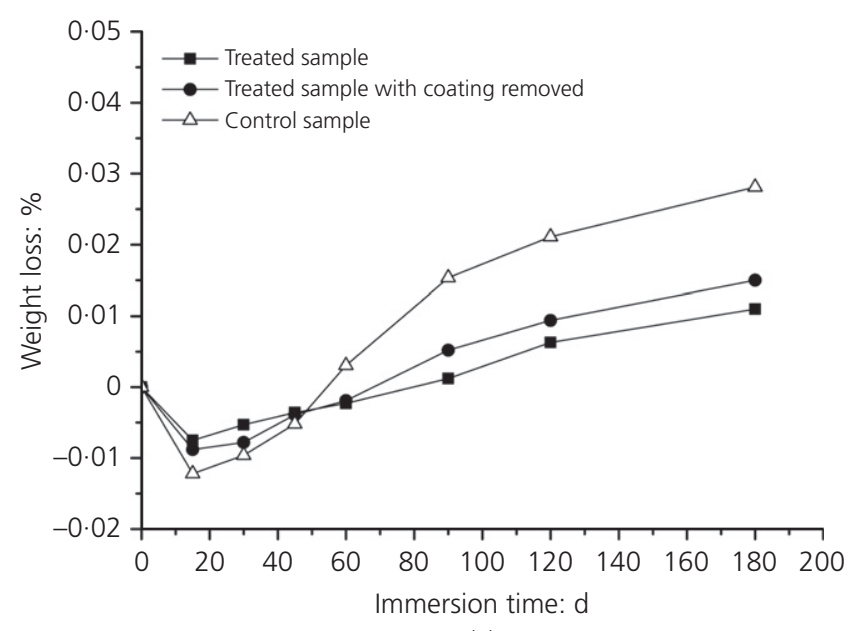

(a)

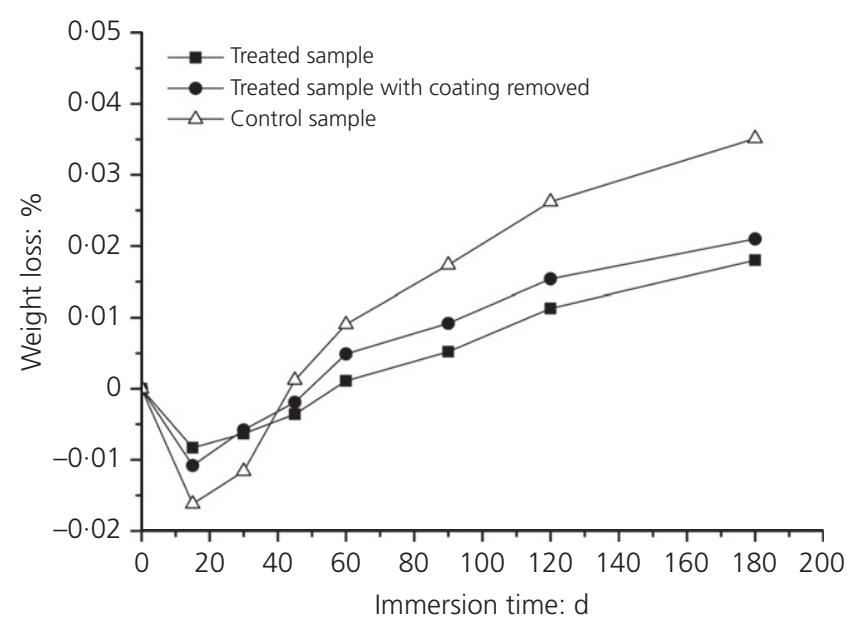

(b)

Figure 7. Weight losses of mortars as a function of immersion time: (a) $w / c=0.45 ;(b) w / c=0.55$

mortar. In addition, the reduction in chloride diffusion coefficient between the control sample and the treated sample with coating removed was greater than that between the treated sample with coating removed and the treated sample. The results in Figures 9(a) and 9(b) show that, compared with the control mortar, the reductions in the chloride diffusion coefficients of the treated mortars with w/c ratios of 0.45 and 0.55 were $47 \cdot 9 \%$ and $41 \cdot 6 \%$, respectively.

\section{Microscopic observations}

An SEM image of the coating layer formed on the mortar surface by the electrochemical treatment is shown in Figure 10(a). Numerous micron-sized pores (about 1-5 $\mu \mathrm{m}$ ) can be seen in the coating layer. SEM images of the control mortar and the treated mortar are shown in Figures 10(b) and 10(c), respectively. These images show that there were many micron-sized pores (about $50 \mu \mathrm{m}$ ) in the control mortar and there were fewer micron-sized pores in the treated mortar.

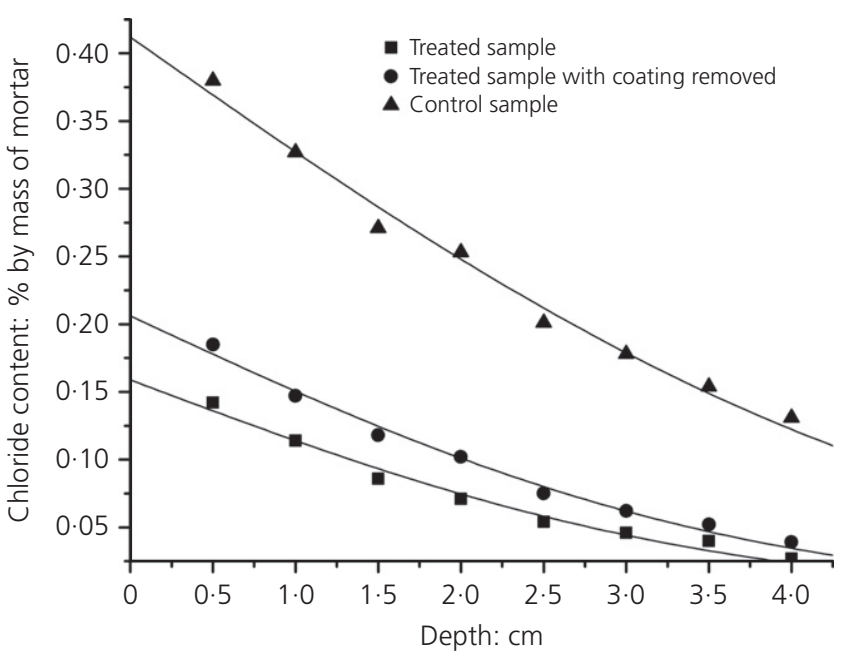

(a)

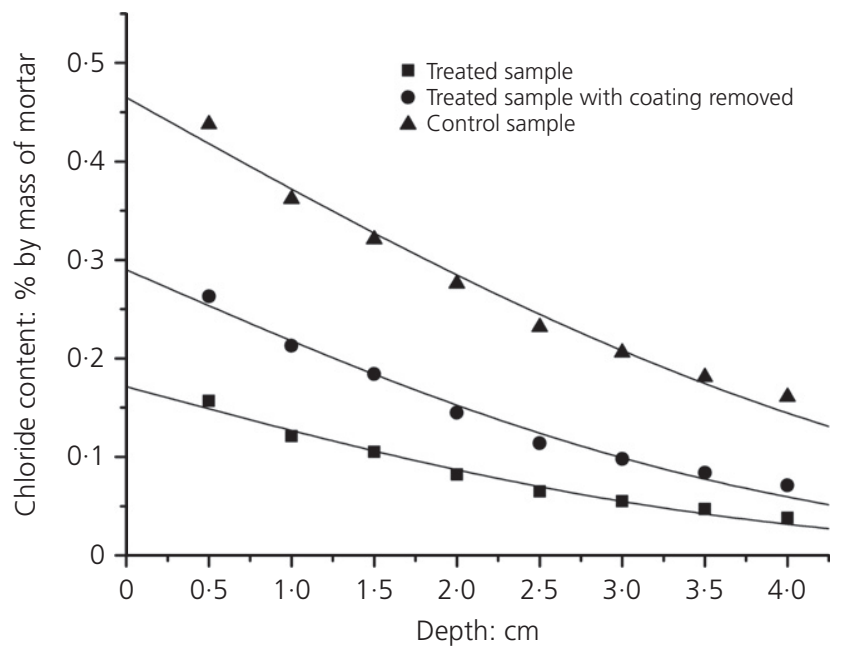

(b)

Figure 8. Chloride profiles of mortars after $90 \mathrm{~d}$ salt immersion: (a) $w / c=0.45 ;(b) w / c=0.55$

Figure 11 shows the pore size distributions of the treated and control mortars. Compared with the control sample, the number of small pores in the treated mortar sample was obviously greater. The critical pore diameters (corresponding to the highest peaks) of the treated mortar decreased from $145.2 \mathrm{~nm}$ to $46.8 \mathrm{~nm}$. Furthermore, compared with the control, the proportion of pores of detrimental size $(\geq 100 \mathrm{~nm})$ and the porosity of the treated mortar were reduced by $4.66 \%$ and $1 \cdot 43 \%$, respectively.

Figure 12 shows the TGA and DSC curves for the treated and control mortars. As shown in the figures, there were peaks in the temperature regions $100-150^{\circ} \mathrm{C}, 360-470^{\circ} \mathrm{C}$ and $700-800^{\circ} \mathrm{C}$. The peaks in the first, second and third region were due to the decomposition of calcium silicate hydrate $(\mathrm{C}-\mathrm{S}-\mathrm{H})$, calcium hydroxide and calcium carbonate, respectively (Kumar et al., 2012). The contents of C-S-H in the 
Advances in Cement Research Volume 29 Issue 10
Improvement of mortar durability

by electrochemical technique

Shan, Xu, Jiang and Wang

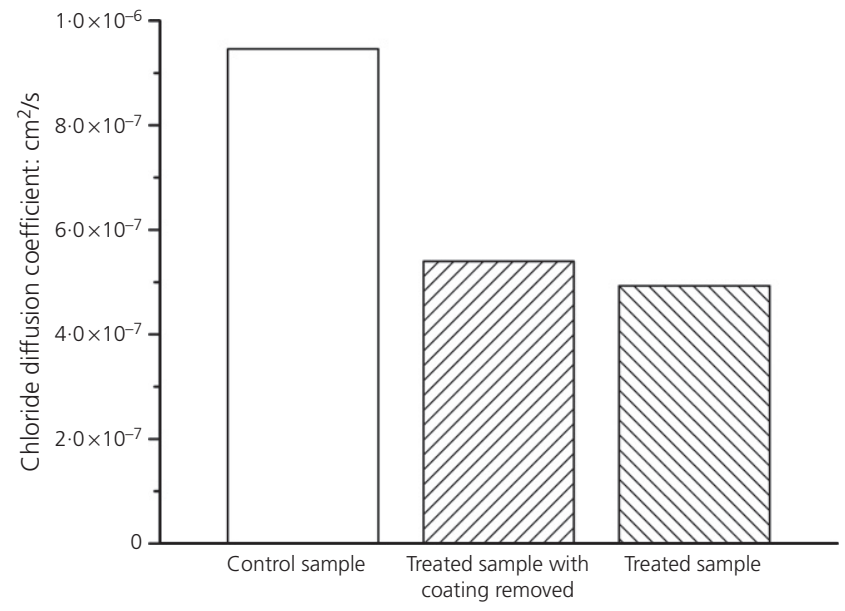

(a)

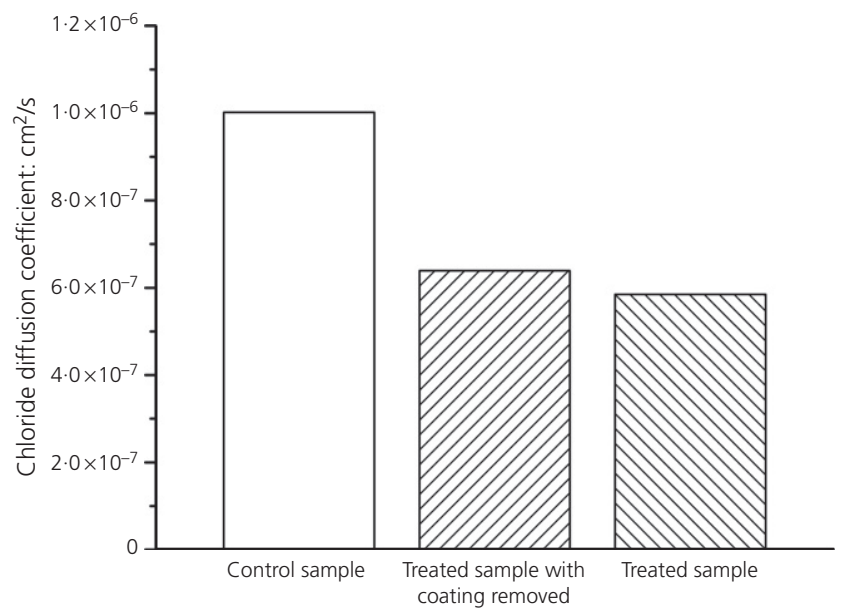

(b)

Figure 9. Chloride diffusion coefficients of mortars: (a) $w / c=0.45 ;(b) w / c=0.55$

treated and control mortars, corresponding to the weight loss, were determined to be $2.75 \%$ and $1.61 \%$, respectively. Likewise, the calcium hydroxide contents in the treated and control mortars were determined to be $2 \cdot 35 \%$ and $1 \cdot 04 \%$, respectively.

\section{Discussion}

Based on the results of durability tests, the water absorption coefficients of the treated samples were smaller than that of the control sample. The reductions in the water absorption coefficient were more than $30 \%$ and it can thus be concluded that the applied electrochemical technique is efficient in inhibiting water absorption by capillary forces. This is an important factor because penetrating water can act as an intermediary for sulfate or chloride penetration, which influences the durability of mortar. Further evidence of improved mortar durability is in the results of sulfate resistance and chloride-ion diffusion. Similar to the water absorption coefficient, the resistance modulus of flexural strength, weight loss and chloride

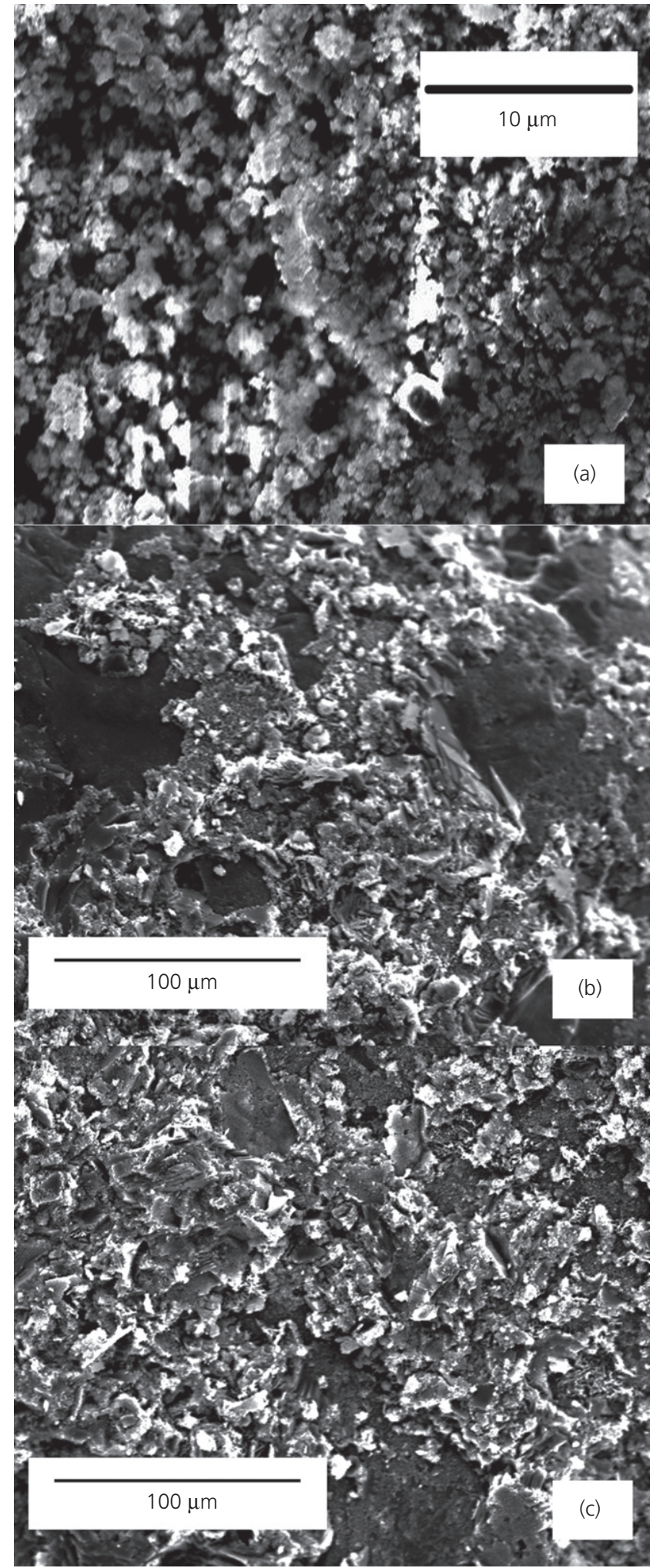

Figure 10. SEM images of (a) the coating layer formed on the mortar surface, (b) the control mortar and (c) the electrochemically treated mortar 


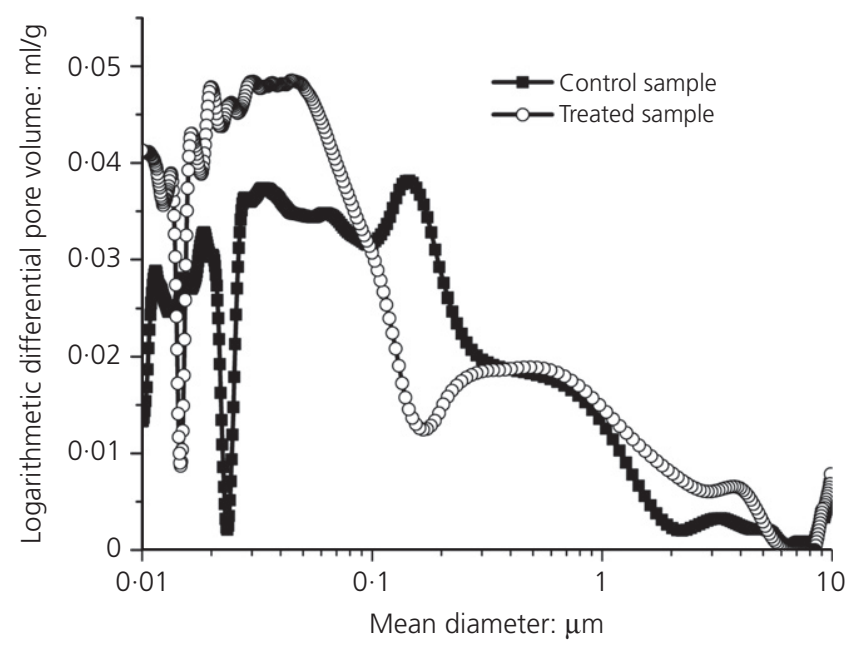

Figure 11. Pore size distributions of control and treated mortars

diffusion coefficients of the treated mortars were all smaller (by more than $40 \%$ ) than those of the control mortar. Accordingly, the proposed electrochemical technique can restrain chloride and sulfate diffusion into mortar. Figure 5 shows that the treated mortars also had a decreased carbonation depth. Therefore, the electrochemical technique can also prevent carbon dioxide diffusing into the mortar. In summary, the technique efficiently improved the resistance to water absorption, carbonation, sulfate attack and chloride diffusion.

The electrochemical technique resulted in a surface coating layer, as shown in Figure 2. The thickness of the surface coating was only about $1.0 \mathrm{~mm}$, and its main components were C-S-H gel and silica gel (Xu et al., 2016). Based on the mortar durability tests, there were only small differences between the water absorption coefficients, carbonation depths, resistance moduli of flexural strength and chloride diffusion coefficients of the treated mortar and the treated mortar with coating removed, indicating that, compared with the densification of the mortars, the coating layer had little effect on preventing the diffusion of aggressive substances into the mortar. This is probably related due the very small thickness and the porous structure of the coating layer (see Figure 9(a)), which may provide channels for corrosive media and thus limit the improvement of mortar durability. It can be concluded that both the coating layer and the densification played roles in improving mortar durability, but the coating layer only played a minor role.

It is well known that the pore size distribution and porosity have significant influences on the durability of mortar. As shown in Figure 10, the treated mortar had a smaller pore size and lower porosity than the control mortar and the number of pores of detrimental size $(\geq 100 \mathrm{~nm})$ was greatly reduced after the electrochemical treatment, thus improving the resistance of the mortar to aggressive substances. The amount of macropores (about $50 \mu \mathrm{m}$ ) in the treated mortar was also less than in

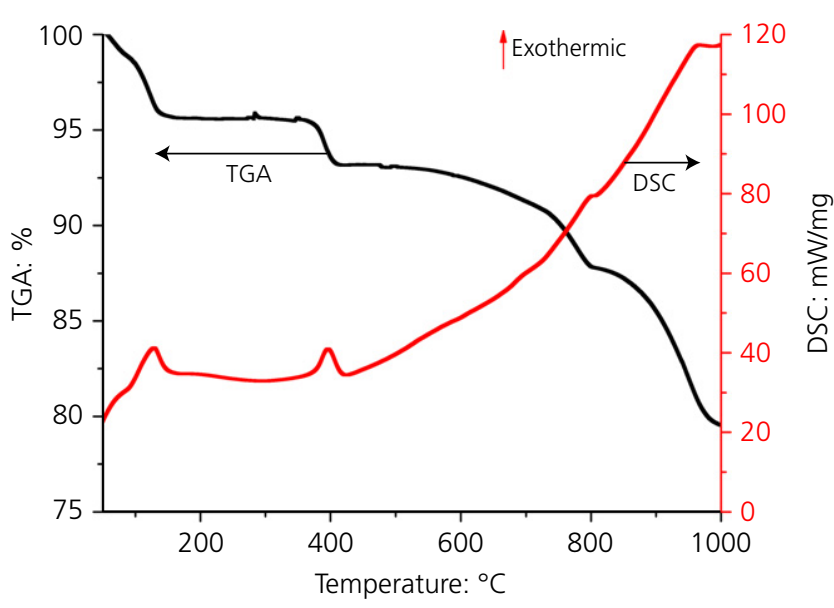

(a)

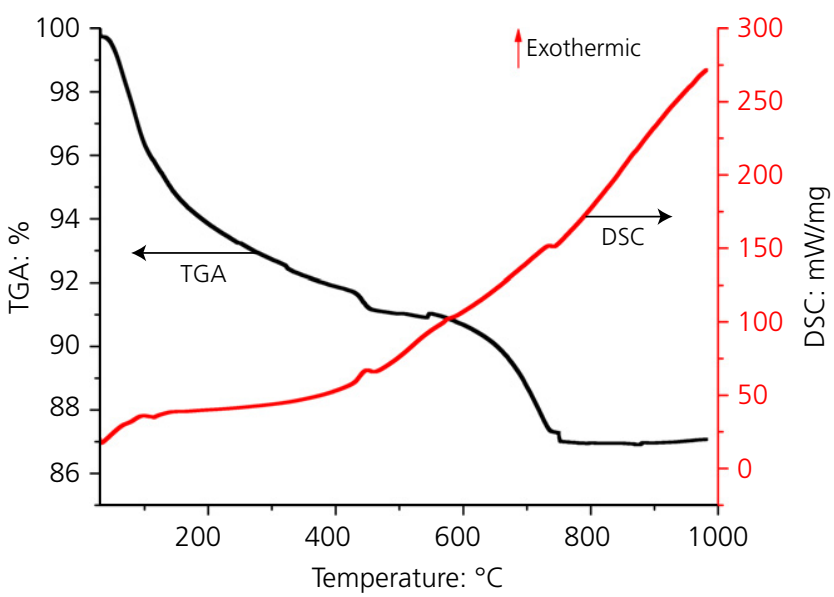

(b)

Figure 12. TGA and DSC curves of (a) treated mortar and (b) control mortar

the control mortar, as shown in Figures 9(b) and 9(c). In a previous study, needle-shaped $\mathrm{C}-\mathrm{S}-\mathrm{H}$ gels were observed in the pores of electrochemically treated mortar specimens (Xu et al., 2016). Filling of the pores by these additional C-S-H gels clearly leads to a decrease in pore size. Further evidence of this is provided in Figure 12: at the same mortar age, the $\mathrm{C}-\mathrm{S}-\mathrm{H}$ gel and calcium hydroxide contents of the electrochemically treated mortars were greater than those of the control mortar.

Mortar with a high w/c ratio has a higher porosity than mortar with a low w/c ratio. Therefore, at the beginning of the electrochemical technique, the mortar with the higher w/c ratio allowed more calcium and silicate ions to penetrate, thus generating the $\mathrm{C}-\mathrm{S}-\mathrm{H}$ gel that blocked pores in the mortar surface quickly. However, densification of the mortar surface prevented silicate ions electro-transporting into the inside of the mortar, resulting in the reduced effectiveness of the electrochemical technique for mortar densification. The reductions in water absorption coefficient, carbonation depths at the same carbonation time, resistance moduli of flexural strength and chloride 
Advances in Cement Research

Volume 29 Issue 10
Improvement of mortar durability

by electrochemical technique

Shan, Xu, Jiang and Wang diffusion coefficients of the treated mortars indicate that the electrochemical technique may be more effective on mortar with a low w/c ratio.

Compared with conventional methods, the electrochemical technique has some specific merits for improving mortar durability. For example, the electrochemical technique can lead to the deposition of materials similar in composition to cement in the pores. In addition, the technique can be applied to both fresh concrete and existing concrete structures. For example, application of the technology to carbonated concrete will improve the alkalinity of the concrete and the carbonation resistance. The technology can also be combined with electrochemical chloride extraction to remove chloride ions in concrete and improve the chloride penetration resistance.

\section{Conclusions}

The proposed electrochemical technique can greatly improve resistance to water absorption, carbonation, sulfate attack and chloride diffusion. Compared with the control mortar, the electrochemically treated mortars showed a reduction in the water absorption coefficient of about $30 \%$ and more than $40 \%$ reduction in carbonation depth, resistance modulus of flexural strength, weight loss and chloride diffusion coefficient. This improvement in mortar durability can be attributed to the combined actions of densification and the production of a coating layer on the mortar surface during the electrochemical treatment. However, the results showed that the coating layer had only a small influence on the improvement of mortar durability.

\section{Acknowledgements}

The authors gratefully acknowledge support from the Natural Science Foundation of China (51278168, 51478164 and 51278167) and Fundamental Research Funds for the Central Universities (2016B45514).

\section{REFERENCES}

Abuawad IMA, Al-Qadi IL and Trepanier JS (2015) Mitigation of moisture damage in asphalt concrete: testing techniques and additives/ modifiers effectiveness. Construction and Building Materials 84: 437-443, https://doi.org/10.1016/j.conbuildmat.2015.03.001

Almusallam AA, Khan FM, Dulaijan SU and Al-Amoudi OSB (2003) Effectiveness of surface coatings in improving concrete durability. Cement \& Concrete Composites 25(4): 473-481.
Badogiannisa EG, Sfikasa IP, Voukiaa DV, Trezosa KG and Tsivilisb SG (2015) Durability of metakaolin self-compacting concrete. Construction and Building Materials 82: 133-141, https://doi.org/ 10.1016/j.conbuildmat.2015.02.023.

Bharatkumar BH, Narayanan R, Raghuprasad BK and Ramachandramurthy DS (2001) Mix proportioning of high performance concrete. Cement \& Concrete Composites 23(1): 71-80.

Chu HQ, Jiang LH, Xiong CS, You LS and Xu N (2014) Use of electrochemical method for repair of concrete cracks. Construction and Building Materials 73: 58-66, https://doi.org/10.1016/j. conbuildmat.2014.09.031.

Faleschini F, Fernández-Ruíz MA, Zanini MA et al. (2015) High performance concrete with electric arc furnace slag as aggregate: mechanical and durability properties. Construction and Building Materials 101: 113-121, https://doi.org/10.1016/j.conbuildmat. 2015.10.022.

ISO (2002) EN 15148:2002: Hygrothermal performance of building materials and products - determination of water absorption coefficient by partial immersion. ISO, Geneva, Switzerland.

Jiang Z, Xing F, Sun Z and Wang P (2008) Healing effectiveness of cracks rehabilitation in reinforced concrete using electrodeposition method. Journal of Wuhan University of Technology - Materials Science Edition 23(6): 917-922.

Kumar M, Singh NP, Sing SK and Singh NB (2012) Tertiary biocomposite cement and its hydration. Construction and Building Materials 29: 1-6, https://doi.org/10.1016/j.conbuildmat.2011.09.017.

Medin NF, Barlueng G and Hernández-Olivares F (2015) Combined effect of polypropylene fibers and silica fume to improve the durability of concrete with natural pozzolans blended cement. Construction and Building Materials 96: 556-566, https://doi.org/10.1016/j.conbuildmat.2015.08.050.

Neville A and Aitcin PC (1998) High performance concrete-an overview. Materials and Structures 31(2): 111-117.

Pritzl MD, Tabatabai H and Ghorbanpoor A (2015) Long-term chloride profiles in bridge decks treated with penetrating sealer or corrosion inhibitors. Construction and Building Materials 101: 1037-1046, https://doi.org/10.1016/j.conbuildmat.2015.10.158.

Ryou JS and Otsuki N (2005) Experimental study on repair of concrete structural members by electrochemical method. Scripta Materialia 52(11): 1123-1127.

Ryu JS and Otsuki N (2002) Crack closure of reinforced concrete by electro-deposition technique. Cement and Concrete Research 32(1): $159-164$.

Shi X, Xie N, Fortune K and Gong J (2012) Durability of steel reinforced concrete in chloride environments: an overview. Construction and Building Materials 30: 125-138, https://doi.org/10.1016/ j.conbuildmat.2011.12.038.

Xu JX, Shan HY, Zhang CK et al. (2016) Surface coating treatment and densification of mortar by electrodeposition method. Magazine of Concrete Research 68(2): 69-79, http://dx.doi.org/10.1680/macr. 15.00042 .

\section{How can you contribute?}

To discuss this paper, please submit up to 500 words to the editor at journals@ice.org.uk. Your contribution will be forwarded to the author(s) for a reply and, if considered appropriate by the editorial board, it will be published as a discussion in a future issue of the journal. 